\title{
Changes in breastfeeding initiation at hospital discharge between first and second births in Nova Scotia: a population- based cohort study
}

\author{
Kimberley Nix BHSc, Linda Dodds PhD
}

\section{Abstract}

Background: Breastfeeding has well-recognized health benefits for infants and mothers. However, little research has been conducted to investigate changes in breastfeeding from one pregnancy to another. This study was conducted to describe rates of breastfeeding initiation at hospital discharge for women's first and second births and to identify factors associated with changes in initiation at the second birth.

Methods: We conducted a longitudinal, population-based cohort study involving women residing in Nova Scotia who delivered a first and second live-born singleton between 2007 and 2013. Separate analyses were conducted among women who breastfed their first infant and among women who did not breastfeed their first infant.

Results: Of the 9643 (82.6\%) mothers who initiated breastfeeding in the first birth, $973(10.3 \%)$ did not initiate breastfeeding in the second birth. Of first-birth noninitiators, $526(26.3 \%)$ initiated breastfeeding in the second birth. With the exception of smoking and cesarean births, factors that were associated with breastfeeding initiation in the second birth depended on breastfeeding initiation status in the first birth. These factors were associated with increased odds of not breastfeeding in the second birth among the subset of mothers who breastfed in the first birth, and decreased odds of breastfeeding in the second birth among the subset of mothers who did not breastfeed in the first birth.

Interpretation: Most women continue the same method of infant feeding after their first and second births. Identifying factors associated with change in breastfeeding status between the first and second births may help to inform interventions for optimal breastfeeding initiation in the second birth.

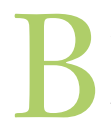

reastfeeding has well-recognized health benefits for both infants and mothers. ${ }^{1-3}$ Breastfeeding is unequalled by alternative feeding methods for both providing ideal nutrition for development and growth of the child, ${ }^{3}$ and reducing long-term health care costs. ${ }^{4}$ Current guidelines from the World Health Organization (WHO) recommend exclusive breastfeeding for the first 6 months of life. $^{2}$ Atlantic Canada has lower rates of breastfeeding than other areas in Canada. ${ }^{5}$ About $83 \%$ of Nova Scotian women breastfed at hospital discharge in 2013, exclusively or with supplementation, which was increased from $73.5 \%$ in $2006 .{ }^{6}$

Numerous studies have been conducted to identify factors associated with breastfeeding initiation. ${ }^{6-17}$ Factors found to be associated with breastfeeding initiation included increasing maternal age, ${ }^{7}$ exclusive prenatal care by midwives, ${ }^{7}$ continued support from professionals such as lactation consultants and peers, ${ }^{9,10}$ sociodemographic factors such as higher levels of education, married or common-law status ${ }^{17}$ and higher household incomes. ${ }^{13}$ Factors associated with lower rates of breast- feeding initiation were multiple births, preterm birth, not attending antenatal classes, ${ }^{6}$ having a high body mass index $(\mathrm{BMI})^{9,10}$ and being an adolescent parent. ${ }^{9,12,14,15}$ These factors relate to breastfeeding status for a single pregnancy and do not consider reasons for changes in breastfeeding status between 2 pregnancies. Some studies have investigated maternal and obstetric factors associated with breastfeeding across multiple pregnancies. ${ }^{8,16-18}$ Overall, the findings showed a decrease in breastfeeding rates among multiparous women compared with primiparous women, ${ }^{17}$ and suggested that unsuccessful breastfeeding with the first child reduced initia-

\section{Competing interests: None declared.}

This article has been peer reviewed.

Correspondence to: Linda Dodds, I.dodds@dal.ca

CMAJ Open 2017. DOI:10.9778/cmajo.20160116 
tion in subsequent births. Although most of these studies had large sample sizes, they did not look at the direction of change of the risk factors between the first and subsequent births

The objectives of this study were to describe the rates of breastfeeding initiation at hospital discharge in first and second births in Nova Scotia and to identify pregnancy and newborn factors associated with a change in breastfeeding initiation.

\section{Methods}

\section{Study design and setting}

We conducted a longitudinal, retrospective cohort study using population-based data from Nova Scotia. Nova Scotia, as with the rest of Canada, has universal health insurance coverage for medical services for residents of the province. More than $95 \%$ of the Nova Scotia population is white, and most births in Nova Scotia occur in a hospital (> 99\%). In 2013, the median maternal postnatal stay in hospital after delivery was about 45 hours for women with a vaginal delivery and 72 hours for women who had a cesarean delivery. ${ }^{19}$

\section{Sources of data}

The Nova Scotia Atlee Perinatal Database (NSAPD) is a compilation of information from each hospital that provides obstetric services and registered midwives in the province. Variables are captured for the Canadian Institute for Health Information Discharge Abstract Database, and additional variables are obtained specifically for the NSAPD. The database includes information on maternal, sociodemographic, prenatal, labour, delivery and neonatal factors. An ongoing quality assurance program is conducted to ensure the data are accurately coded. These activities include chart review audits conducted on annual hospital visits and comparisons of the NSAPD to administrative health data. ${ }^{20}$

\section{Population}

Nova Scotia residents who had their first birth (e.g., nulliparous women) and second birth (e.g., primiparous women) between Jan. 1, 2007, and Dec. 31, 2013, were included. If a woman had more than 2 pregnancies during the study period, only the first 2 pregnancies were included. This study was limited to singleton births (in both the first and second births), both infants with birth weight $500 \mathrm{~g}$ or more, and both infants surviving 28 days or more. Women with missing breastfeeding information for the first or second births were excluded.

\section{Variables and definitions}

The outcome of "any breastfeeding" was described as exclusive or supplemental breastfeeding at hospital discharge, "yes" or "no," in line with Labbok and Krasovec's definitions of breastfeeding. ${ }^{21}$ Breastfeeding initiation was evaluated at the second birth and assessed to identify a change in initiation from the first birth; for women who initiated any breastfeeding in the first birth, the outcome variable was no breastfeeding initiation in the second birth; for women who did not ini- tiate any breastfeeding in the first birth, the outcome variable was any breastfeeding in the second birth.

Explanatory variables were selected based on previous literature of factors associated with breastfeeding initiation or factors potentially affecting a woman's ability to breastfeed. These factors included maternal sociodemographic variables (maternal age, any smoking during pregnancy [yes/no], preconceptual folate intake [yes/no], obesity, as defined by prepregnancy weight of more than $90 \mathrm{~kg}$ [yes/no], neighbourhood income, defined as quintiles of neighbourhood income per single person equivalent based on postal code linked to Canadian census data [low/lowest or mid-highest], rural location based on postal code [yes/no], married or common law [yes/no], inter birth interval of less than 18 months [yes/no]), maternal health conditions during pregnancy (maternal recreational drug use [yes/no], gestational diabetes mellitus [yes/ no], pre-existing diabetes [yes/no], gestational hypertension [yes/no], carrier status positive or chronic infection during pregnancy of cytomegalovirus, group B strep, herpes simplex, HIV/AIDS, syphilis, toxoplasmosis, or hepatitis A, B or C [yes/no], admission to hospital for hyperemesis [yes/no]), labour and delivery factors (labour onset [none v. induced/ spontaneous], cesarean delivery [yes/no], obstetrician attending delivery [yes/no], tertiary delivery hospital [yes/no], thirdor fourth-degree perineal tear [yes/no], postpartum hemorrhage [yes/no], epidural analgesia [yes/no], spinal analgesia [yes/no], regional analgesia [yes/no]) andinfant factors (birth sex [male or female], birth weight $\geq 2500 \mathrm{~g}$ [yes/no], Apgar at 0 and 5 minutes $<7$ [yes/no], birth year [2006-2009, 2010 2011, 2012-2013], special care nursery stay $\geq 72 \mathrm{~h}$ [yes/no], major head or neck anomaly [yes/no], other major anomaly [yes/no], gestational age $<37$ weeks [yes/no], infant length of hospital stay $\geq 72$ hours [yes/no], hyperbilirubenemia diagnosed or phototherapy received [yes/no]).

Factors were modelled for each possibility of change over time between first and second births. This approach was taken so that we could identify exposure changes that might be associated with changes in breastfeeding status from the first birth to the second birth, which in turn could help identify subgroups of women to target for intervention strategies. For example, "any smoking" has the following options for change over time: a person may have remained a smoker during the first and second birth, become a nonsmoker in the second birth (after smoking in the first birth), become a smoker in second birth (after being a nonsmoker in the first birth) or remained a nonsmoker for both the first and second births. All variables were modelled with this approach with the exception of time-dependent variables such as maternal age and birth year.

\section{Statistical analysis}

Factors evaluated in the study were first analyzed using descriptive statistics and were reported as numbers and percentages. A univariate analysis was conducted for the 2 subsets of the cohort: one for women who initiated breastfeeding in the first birth, and a separate model for mothers who did not initiate breastfeeding in the first birth. Factors included in the 
initial logistic regression models were those that had a $p$ value of 0.10 or less on $\chi^{2}$ test from the bivariate analysis. Variables were eliminated from the model if they did not contribute to the fit of the regression model at a $p$ value of less than 0.05 , as determined by a likelihood ratio test. These logistic regression models were used to estimate adjusted odds ratios (ORs) and $95 \%$ confidence intervals (CIs) for each covariate. A complete case analysis was conducted, with the final models including only observations with nonmissing values for each factor. All analyses were conducted using SPSS 22.0.

\section{Ethics approval}

This study received data access approval from the Data Access Committee of the Reproductive Care Program, as well as approval from the Research Ethics Board at the IWK Health Centre.

\section{Results}

There were 11800 Nova Scotia residents who had their first and second births between Jan. 1, 2007, and Dec. 31, 2013. After excluding women who did not have a singleton birth of an infant weighing $500 \mathrm{~g}$ or more in both the first and the second births (264 women), there were 76 additional women excluded because of missing breastfeeding information for either the first or second birth, leaving 11460 women for analyses in this study. Figure 1 shows the breastfeeding initiation status at the first birth and the second birth for the 11460 women who were included in the study. Of the 9463 $(82.6 \%)$ women who initiated breastfeeding in the first birth, $8490(89.7 \%)$ also initiated breastfeeding in the second birth. Of the 1997 (17.4\%) women who did not initiate in the first birth, 1471 (73.7\%) remained noninitiators for both children.

Table 1 describes the population characteristics of the cohort, with frequencies shown according to their presence in each pregnancy. Factors containing categories with fewer than 5 participants are not shown in accordance with data access requirements. The mean maternal age at the second birth, among women who initiated breastfeeding in the first birth, was 30.3 years, whereas it was 26.2 years among women who did not breastfeed in the first birth. For the factors congenital abnormalities and neonatal intensive care unit (NICU) stay, analyzing the variables with respect to change in exposure status between birth 1 and birth 2 was not possible because there were too few observations in some categories (e.g., very few women have infants with a congenital anomaly in their first and second births). Therefore, these 2 exposure variables were analyzed at the second birth only.

Table 2 shows the unadjusted and adjusted odds ratios of not breastfeeding in the second birth, among the subset of women who breastfed in the first birth. Becoming or remaining a smoker, changing to a higher or remaining in a lowincome neighbourhood, having a cesarean delivery in the second birth or in both births, not supplementing with folic acid preconceptually in both births, nontertiary hospital in the second birth or in both births, recreational drug use in the second birth, and younger maternal age were significantly associated with the odds of not breastfeeding in the second birth.

Table 3 shows the unadjusted and adjusted ORs of breastfeeding in the second birth among the subset of women who did not breastfeed in the first birth. Smoking in both the first and second births, birth year for the second birth in an earlier epoch, and having a cesarean delivery in both the first and second births were significantly associated with decreased odds of breastfeeding in the second birth. Infant length of stay of 72 hours or more in NICU for both the first and second births was associated with increased odds of breastfeeding in the second birth (OR 2.30, CI 1.58-3.35).

\section{Interpretation}

Our data show that most women do not change their breastfeeding status between their first 2 births. Of the women who initiated breastfeeding in the first birth, $10 \%$ did not initiate

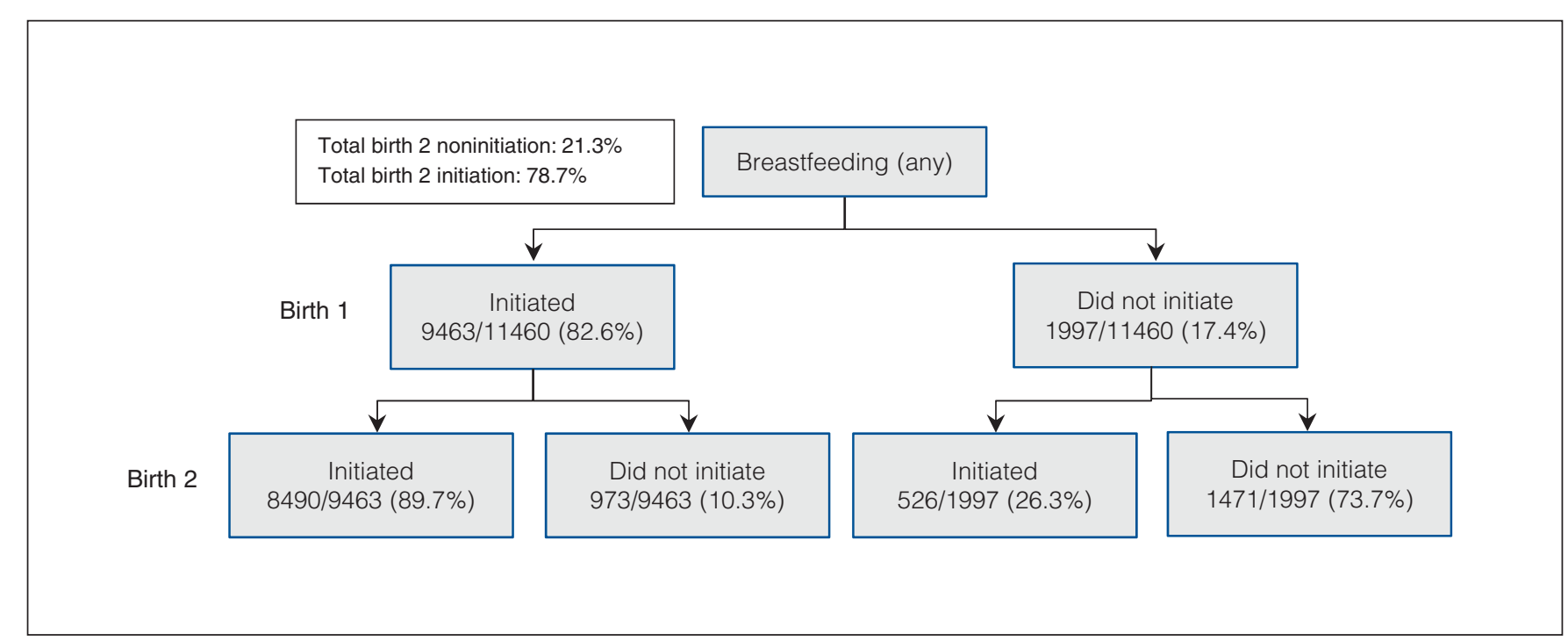

Figure 1: Breastfeeding initiation at hospital discharge at birth 1 and birth 2, Nova Scotia, 2007-2013 ( $n=11460$ women, 22920 pregnancies). 


\section{OPEN}

Research

breastfeeding in the second birth. Of the women who did not initiate breastfeeding in the first birth, $26 \%$ did initiate breastfeeding in the second birth. Only 2 factors (smoking and cesarean delivery) were associated with both directions of change in breastfeeding initiation (e.g., initiation in the first, but not second birth; noninitiation in the first, but initiation in the second birth). Our study incorporated information on risk factors from both birth 1 and birth 2, which provided additional insight into reasons for breastfeeding changes. For example, cesarean delivery was significantly associated with breastfeeding status in the second birth only when a woman had had a cesarean delivery for both births. With the exception of cesarean delivery and hospital type, factors associated with changing from breastfeeding initiation in the first birth to noninitiation in the second birth were mainly lifestyle and sociodemographic factors. In contrast, for the women who initiated breastfeeding the in second birth after not breastfeeding in the first birth, smoking was the only lifestyle or sociodemographic factor identified.

Our finding that women tend to continue with the same infant feeding practices in their first 2 births is in keeping with similar studies conducted in the United States ${ }^{16}$ and in Australia. ${ }^{8}$ Phillips and colleagues extended their research to look at duration of exclusive breastfeeding across births and found that women tended to breastfeed for similar durations from one birth to another. ${ }^{17}$ In addition to similarities regarding the

\begin{tabular}{|c|c|c|c|c|c|c|c|c|}
\hline \multirow[b]{2}{*}{ Factor } & \multirow[b]{2}{*}{ Birth 1} & \multirow[b]{2}{*}{ Birth 2} & \multicolumn{3}{|c|}{$\begin{array}{l}\text { Birth } 1 \text { breastfeeding initiators } \\
\qquad(n=9463)\end{array}$} & \multicolumn{3}{|c|}{$\begin{array}{l}\text { Birth } 1 \text { breastfeeding noninitiators } \\
\qquad(n=1997)\end{array}$} \\
\hline & & & $\begin{array}{c}\text { No. } \\
\text { breastfed } \\
\text { B1 }\end{array}$ & $\begin{array}{c}\% \text { Did not } \\
\text { breastfeed } \\
\text { B2 }\end{array}$ & $p$ value & $\begin{array}{l}\text { No. did not } \\
\text { breastfeed } \\
\quad \text { B1 }\end{array}$ & $\begin{array}{c}\% \\
\text { Breastfed } \\
\text { B2 }\end{array}$ & $p$ value \\
\hline \multicolumn{9}{|l|}{ Sociodemographic } \\
\hline $\begin{array}{l}\text { Maternal age birth 2, yr, } \\
\text { mean } \pm \mathrm{SD}\end{array}$ & \multicolumn{2}{|l|}{-} & \multicolumn{2}{|c|}{$30.3 \pm 5.0$} & & \multicolumn{2}{|c|}{$26.2 \pm 5.1$} & \\
\hline \multirow[t]{4}{*}{ Smoking } & No & No & 7075 & 8.2 & \multirow[t]{4}{*}{$<0.001$} & 940 & 29 & \multirow[t]{4}{*}{0.01} \\
\hline & No & Yes & 246 & 20.7 & & 86 & 31.4 & \\
\hline & Yes & No & 369 & 13.6 & & 138 & 28.3 & \\
\hline & Yes & Yes & 880 & 24.5 & & 698 & 22.2 & \\
\hline \multirow[t]{4}{*}{ Folic acid } & Yes & No & 2803 & 5.6 & \multirow[t]{4}{*}{$<0.001$} & 184 & 28.3 & \multirow[t]{4}{*}{0.07} \\
\hline & Yes & Yes & 1017 & 8.8 & & 131 & 26.7 & \\
\hline & No & No & 994 & 7.9 & & 161 & 35.4 & \\
\hline & No & Yes & 1929 & 17.8 & & 820 & 25.2 & \\
\hline \multirow[t]{4}{*}{ Maternal obesity } & No & No & 4333 & 9.3 & \multirow[t]{4}{*}{$<0.001$} & 840 & 25.2 & \multirow[t]{4}{*}{0.6} \\
\hline & No & Yes & 287 & 15.7 & & 55 & 20 & \\
\hline & Yes & No & 352 & 11.6 & & 102 & 29.4 & \\
\hline & Yes & Yes & 1893 & 12 & & 455 & 26.2 & \\
\hline \multirow[t]{4}{*}{ High income area } & Yes & Yes & 4048 & 7.9 & \multirow[t]{4}{*}{$<0.001$} & 662 & 27 & \multirow[t]{4}{*}{0.1} \\
\hline & Yes & No & 533 & 13.1 & & 155 & 34.2 & \\
\hline & No & Yes & 649 & 14.3 & & 144 & 27.1 & \\
\hline & No & No & 2271 & 13.6 & & 695 & 24.7 & \\
\hline \multirow[t]{4}{*}{ Rural residence } & No & No & 3550 & 8.9 & \multirow[t]{4}{*}{$<0.001$} & 1188 & 25.6 & \multirow[t]{4}{*}{0.7} \\
\hline & No & Yes & 353 & 12.5 & & 98 & 28.6 & \\
\hline & Yes & No & 253 & 13 & & 75 & 30.7 & \\
\hline & Yes & Yes & 2213 & 13.6 & & 619 & 27 & \\
\hline \multirow[t]{4}{*}{ Married } & Yes & Yes & 6174 & 7 & \multirow[t]{4}{*}{$<0.001$} & 588 & 25.9 & \multirow[t]{4}{*}{0.8} \\
\hline & Yes & No & 157 & 17.8 & & 55 & 30.9 & \\
\hline & No & Yes & 1019 & 14 & & 321 & 27.7 & \\
\hline & No & No & 1069 & 20.4 & & 653 & 27 & \\
\hline \multirow[t]{2}{*}{ Interpregnancy interval } & \multicolumn{2}{|c|}{$<18 \mathrm{mo}$} & 998 & 17.1 & \multirow[t]{2}{*}{$<0.001$} & 294 & 24.5 & 0.4 \\
\hline & & mo & 8465 & 9.5 & & 1703 & 26.7 & \\
\hline
\end{tabular}




\begin{tabular}{|c|c|c|c|c|c|c|c|c|}
\hline \multirow[b]{2}{*}{ Factor } & \multirow[b]{2}{*}{ Birth 1} & \multirow[b]{2}{*}{ Birth 2} & \multicolumn{3}{|c|}{$\begin{array}{l}\text { Birth } 1 \text { breastfeeding initiators } \\
\qquad(n=9463)\end{array}$} & \multicolumn{3}{|c|}{$\begin{array}{l}\text { Birth } 1 \text { breastfeeding noninitiators } \\
\qquad(n=1997)\end{array}$} \\
\hline & & & $\begin{array}{l}\text { No. } \\
\text { breastfed } \\
\text { B1 }\end{array}$ & $\begin{array}{c}\text { \% Did not } \\
\text { breastfeed } \\
\text { B2 }\end{array}$ & $p$ value & $\begin{array}{l}\text { No. did not } \\
\text { breastfeed } \\
\text { B1 }\end{array}$ & $\begin{array}{c}\% \\
\text { Breastfed } \\
\text { B2 }\end{array}$ & $p$ value \\
\hline \multicolumn{9}{|l|}{ Maternal health } \\
\hline \multirow[t]{4}{*}{ Recreational drug use } & No & No & 9221 & 10.1 & \multirow[t]{4}{*}{$<0.001$} & 1850 & 26.1 & \multirow[t]{4}{*}{0.4} \\
\hline & No & Yes & 81 & 17.3 & & 46 & 37 & \\
\hline & Yes & No & 123 & 18.7 & & 83 & 27.7 & \\
\hline & Yes & Yes & 38 & 23.7 & & 18 & 22.2 & \\
\hline \multirow[t]{3}{*}{ Pregestational diabetes } & No & No & 9390 & 10.3 & \multirow[t]{3}{*}{0.6} & 1970 & 26.3 & \multirow[t]{3}{*}{0.3} \\
\hline & No & Yes & 25 & 12 & & 8 & 0 & \\
\hline & Yes & Yes & 40 & 15.6 & & 13 & 38.5 & \\
\hline \multirow[t]{4}{*}{ Gestational diabetes } & No & No & 8966 & 10.1 & \multirow[t]{4}{*}{0.01} & 1892 & 26.4 & \multirow[t]{4}{*}{0.6} \\
\hline & No & Yes & 248 & 10.1 & & 56 & 28.6 & \\
\hline & Yes & No & 126 & 17.5 & & 17 & 11.8 & \\
\hline & Yes & Yes & 123 & 16.3 & & 32 & 28.1 & \\
\hline \multirow[t]{4}{*}{ Hyperemesis } & No & No & 9352 & 10.2 & \multirow[t]{5}{*}{0.1} & 1964 & 26.1 & \multirow[t]{5}{*}{0.09} \\
\hline & No & Yes & 62 & 11.3 & & 18 & 44.4 & \\
\hline & Yes & No & 38 & 18.4 & & 7 & 57.1 & \\
\hline & Yes & Yes & 11 & 27.3 & & 8 & 25 & \\
\hline \multicolumn{7}{|l|}{$\begin{array}{l}\text { Labour and delivery } \\
\text { factors }\end{array}$} & & \\
\hline \multirow[t]{4}{*}{ Labour S/l } & Yes & Yes & 7389 & 9.9 & \multirow[t]{4}{*}{0.03} & 1144 & 26.3 & \multirow[t]{4}{*}{0.01} \\
\hline & Yes & No & 1479 & 12 & & 251 & 23 & \\
\hline & No & Yes & 188 & 6.9 & & 15 & 48.3 & \\
\hline & No & No & 407 & 11.8 & & 6 & 32.2 & \\
\hline \multirow[t]{4}{*}{ Cesarean delivery } & No & No & 6685 & 9.9 & \multirow[t]{4}{*}{0} & 1414 & 25.7 & \multirow[t]{4}{*}{0.06} \\
\hline & No & Yes & 464 & 12.9 & & 111 & 32.4 & \\
\hline & Yes & No & 457 & 4.8 & & 69 & 37.7 & \\
\hline & Yes & Yes & 1855 & 12.2 & & 403 & 25.1 & \\
\hline Ob/Gyn attending & Yes & Yes & 4997 & 11.1 & 0.01 & 1069 & 27.5 & 0.2 \\
\hline & Yes & No & 1144 & 8 & & 232 & 27.6 & \\
\hline & No & Yes & 659 & 10.9 & & 153 & 28.1 & \\
\hline & No & No & 2620 & 9.4 & & 523 & 22.9 & \\
\hline Postpartum hemorrhage & No & No & 8005 & 10.3 & 0.6 & 1711 & 25.5 & 0.03 \\
\hline & No & Yes & 474 & 9.1 & & 97 & 30.9 & \\
\hline & Yes & No & 837 & 10.8 & & 170 & 28.8 & \\
\hline & Yes & Yes & 147 & 8.2 & & 19 & 52.6 & \\
\hline Spinal anesthesia & No & No & 6533 & 9.8 & 0.02 & 1429 & 25.7 & 0.08 \\
\hline & No & Yes & 1644 & 11.6 & & 291 & 24.4 & \\
\hline & Yes & No & 567 & 8.8 & & 84 & 36.9 & \\
\hline & Yes & Yes & 719 & 12.7 & & 193 & 29.5 & \\
\hline
\end{tabular}




\begin{tabular}{|c|c|c|c|c|c|c|c|c|}
\hline \multirow[b]{2}{*}{ Factor } & \multirow[b]{2}{*}{ Birth 1} & \multirow[b]{2}{*}{ Birth 2} & \multicolumn{3}{|c|}{$\begin{array}{l}\text { Birth } 1 \text { breastfeeding initiators } \\
\qquad(n=9463)\end{array}$} & \multicolumn{3}{|c|}{$\begin{array}{l}\text { Birth } 1 \text { breastfeeding noninitiators } \\
\qquad(n=1997)\end{array}$} \\
\hline & & & $\begin{array}{l}\text { No. } \\
\text { breastfed } \\
\text { B1 }\end{array}$ & $\begin{array}{c}\text { \% Did not } \\
\text { breastfeed } \\
\text { B2 }\end{array}$ & $p$ value & $\begin{array}{l}\text { No. did not } \\
\text { breastfeed } \\
\quad \text { B1 }\end{array}$ & $\begin{array}{c}\% \\
\text { Breastfed } \\
\text { B2 }\end{array}$ & $p$ value \\
\hline \multicolumn{9}{|l|}{$\begin{array}{l}\text { Labour and delivery } \\
\text { factors (continued) }\end{array}$} \\
\hline \multirow[t]{4}{*}{ Epidural anesthesia } & No & No & 2758 & 10 & \multirow[t]{4}{*}{0.2} & 666 & 27.9 & \multirow[t]{4}{*}{0.06} \\
\hline & No & Yes & 532 & 9.8 & & 117 & 35 & \\
\hline & Yes & No & 2919 & 11.2 & & 597 & 25.3 & \\
\hline & Yes & Yes & 3254 & 9.7 & & 617 & 24 & \\
\hline \multirow[t]{4}{*}{ Intravenous analgesia } & No & No & 1898 & 8.9 & \multirow[t]{4}{*}{0.1} & 448 & 26.8 & \multirow[t]{4}{*}{0.3} \\
\hline & No & Yes & 497 & 11.7 & & 129 & 32.6 & \\
\hline & Yes & No & 1816 & 10.7 & & 394 & 26.9 & \\
\hline & Yes & Yes & 5252 & 10.5 & & 1026 & 25.1 & \\
\hline \multicolumn{9}{|l|}{ Infant factors } \\
\hline \multirow[t]{2}{*}{ Birth sex } & - & Male & 4921 & 10.2 & \multirow[t]{2}{*}{0.8} & 1034 & 24.6 & \multirow[t]{2}{*}{0.7} \\
\hline & - & Female & 4542 & 10.3 & & 963 & 24.8 & \\
\hline \multirow[t]{4}{*}{ Birth weight $\geq 2500 \mathrm{~g}$} & Yes & Yes & 8923 & 10 & \multirow[t]{4}{*}{$<0.001$} & 1798 & 25.3 & \multirow[t]{4}{*}{0.01} \\
\hline & Yes & No & 163 & 16.6 & & 63 & 28.6 & \\
\hline & No & Yes & 315 & 14 & & 110 & 38.2 & \\
\hline & No & No & 54 & 18.5 & & 24 & 41.7 & \\
\hline \multirow[t]{4}{*}{ Apgar at $1 \mathrm{~min}>6$} & Yes & Yes & 7674 & 9.9 & \multirow[t]{4}{*}{0.1} & 1613 & 24.7 & \multirow[t]{4}{*}{$<0.001$} \\
\hline & Yes & No & 554 & 12.1 & & 124 & 34.7 & \\
\hline & No & Yes & 1080 & 11.7 & & 237 & 31.2 & \\
\hline & No & No & 155 & 11.6 & & 23 & 47.3 & \\
\hline \multirow[t]{3}{*}{ Birth year } & - & 2007-09 & 3819 & 9.2 & 0.01 & 761 & 31.7 & $<0.001$ \\
\hline & - & $2010-11$ & 2280 & 11.6 & & 529 & 20.4 & \\
\hline & - & $2012-13$ & 3364 & 10.6 & & 707 & 25 & \\
\hline NICU admission & - & Yes & 192 & 10.9 & 0.7 & 50 & 44 & $<0.001$ \\
\hline & - & No & 9271 & 10.3 & & 1947 & 25.9 & \\
\hline Head/neck anomaly & - & No & 9440 & 10.3 & 0.07 & 1990 & 26.3 & 0.9 \\
\hline & - & Yes & 23 & 21.7 & & 7 & 28.6 & \\
\hline Other major anomaly & - & No & 9124 & 10.1 & 0.03 & 1900 & 25.7 & 0.01 \\
\hline & - & Yes & 339 & 13.9 & & 97 & 38.1 & \\
\hline Gestational age $\geq 37$ wk & Yes & Yes & 8534 & 10 & 0.03 & 1744 & 24.6 & $<0.001$ \\
\hline & Yes & No & 329 & 14.3 & & 79 & 35.4 & \\
\hline & No & Yes & 453 & 12.1 & & 128 & 37.5 & \\
\hline & No & No & 108 & 13 & & 31 & 51.6 & \\
\hline Infant length of stay $<72 \mathrm{~h}$ & Yes & Yes & 5263 & 10.4 & 0.5 & 1279 & 22.8 & $<0.001$ \\
\hline & Yes & No & 754 & 9.7 & & 200 & 35 & \\
\hline & No & Yes & 2207 & 10.7 & & 324 & 29.3 & \\
\hline & No & No & 1239 & 9.3 & & 194 & 35.6 & \\
\hline Hyperbilirubin & No & No & 6635 & 10.6 & 0 & 1535 & 23.8 & $<0.001$ \\
\hline & No & Yes & 804 & 8.5 & & 156 & 35.3 & \\
\hline & Yes & No & 1471 & 11.5 & & 228 & 28.1 & \\
\hline & Yes & Yes & 553 & 5.8 & & 78 & 53.8 & \\
\hline
\end{tabular}

rates of recurrent infant feeding across births, some of the factors we identified as being associated with changing feeding practices have been reported from other studies.
A recent publication by Bentley and colleagues used population-based data from New South Wales, Australia, to evaluate infant feeding practices across first and second births 
and to identify factors from the second birth that were associated with changes in feeding practices. ${ }^{8}$ Both our study and that of Bentley and colleagues found that smoking, younger age, lower neighbourhood socioeconomic index, cesarean delivery and type of hospital were associated with greater likelihood of switching feeding practices from breastfeeding in the first birth to not breastfeeding in the second. ${ }^{8}$ Similarities between the Nova Scotia and Australia populations were also seen among women who switched from noninitiation in the first birth to initiation in the second birth, where both smoking and cesarean delivery were associated with reduced likelihood of breastfeeding in the second birth. ${ }^{8}$ However, our analysis focused on changes in exposure status across the 2 pregnancies, and included some variables that were not available in the New South Wales database (e.g., drug use, maternal BMI).

A surprising finding was that women who switched from not reporting recreational drug use in the first pregnancy to reporting using recreational drugs in the second pregnancy had decreased odds of not breastfeeding in the second birth. This may be attributable to type 1 error given the number of variables examined; alternatively, mothers using methadone may have received additional appointments with health care providers where breastfeeding was encouraged..$^{22}$ We interpret the importance of preconceptual folic acid as a possible proxy for planning a pregnancy, because women are recommended to start taking folic acid before they become pregnant. ${ }^{23}$ Within the subset of women who did not breastfeed in the first birth, having an infant length of stay of 72 hours or more in both the first and second births increased the odds of breastfeeding in the second birth. We hypothesize that this may be related to the potential supports that may be offered to the mother during this time. Regarding more recent birth year being associated with breastfeeding in the second birth among women who did not breastfeed in the first birth, policy

Table 2: Unadjusted and adjusted analyses showing associations between factors in first and second births and odds of not initiating breastfeeding in the second birth among women who did initiate breastfeeding in the first birth

\begin{tabular}{|c|c|c|c|c|}
\hline Factor & Birth 1 & Birth 2 & $\begin{array}{l}\text { Unadjusted OR } \\
(95 \% \mathrm{Cl})\end{array}$ & $\begin{array}{l}\text { Adjusted OR* } \\
\quad(95 \% \mathrm{Cl})\end{array}$ \\
\hline \multirow[t]{4}{*}{ Smoking } & No & No & 1.00 & 1.00 \\
\hline & No & Yes & $2.91(1.89-4.39)$ & $1.61(1.03-2.52)$ \\
\hline & Yes & No & $1.54(1.01-2.30)$ & $1.02(0.67-1.57)$ \\
\hline & Yes & Yes & $3.13(2.46-3.96)$ & $1.58(1.21-2.08)$ \\
\hline \multirow[t]{4}{*}{ High-income area } & Yes & Yes & 1.00 & 1.00 \\
\hline & Yes & No & $1.50(1.03-2.14)$ & $0.99(0.67-1.45)$ \\
\hline & No & Yes & $1.26(0.87-1.79)$ & $1.54(1.12-2.12)$ \\
\hline & No & No & 1.87 (1.53-2.28) & $1.44(1.17-1.78)$ \\
\hline \multirow[t]{4}{*}{ Cesarean delivery } & No & No & 1.00 & 1.00 \\
\hline & No & Yes & $1.35(0.90-1.97)$ & $1.30(0.96-1.77)$ \\
\hline & Yes & No & $0.46(0.24-0.80)$ & $0.57(0.31-1.05)$ \\
\hline & Yes & Yes & 1.33 (1.08-1.64) & $1.70(1.36-2.13)$ \\
\hline \multirow[t]{4}{*}{ Folic acid } & Yes & Yes & 1.00 & 1.00 \\
\hline & Yes & No & $1.68(1.24-2.26)$ & $1.30(0.96-1.77)$ \\
\hline & No & Yes & 1.44 (1.05-1.97) & $0.99(0.71-1.38)$ \\
\hline & No & No & $3.57(2.86-4.48)$ & $1.78(1.36-2.33)$ \\
\hline \multirow[t]{4}{*}{ Tertiary hospital type } & Yes & Yes & 1.00 & 1.00 \\
\hline & Yes & No & $3.16(2.01-4.85)$ & $2.34(1.47-3.72)$ \\
\hline & No & Yes & $0.80(0.28-1.87)$ & $0.53(0.22-1.44)$ \\
\hline & No & No & 2.03 (1.69-2.45) & $1.54(1.26-1.87)$ \\
\hline \multirow[t]{4}{*}{ Recreational drug use } & No & No & 1.00 & 1.00 \\
\hline & No & Yes & $0.61(0.15-1.77)$ & $0.22(0.07-0.73)$ \\
\hline & Yes & No & $2.33(1.21-4.24)$ & $1.24(0.64-2.38)$ \\
\hline & Yes & Yes & $4.73(1.76-11.8)$ & $2.29(0.87-6.05)$ \\
\hline $\begin{array}{l}\text { Maternal age in birth } 2 \\
\text { (continuous), yr }\end{array}$ & - & - & $0.88(0.87-0.90)$ & $0.92(0.90-0.95)$ \\
\hline
\end{tabular}




\begin{tabular}{|c|c|c|c|c|}
\hline Factor & Birth 1 & Birth 2 & Unadjusted OR $(95 \% \mathrm{Cl})$ & Adjusted OR* $(95 \% \mathrm{Cl})$ \\
\hline \multirow[t]{4}{*}{ Smoking } & No & No & 1.00 & 1.00 \\
\hline & No & Yes & $0.11(0.69-1.80)$ & $1.13(0.70-1.84)$ \\
\hline & Yes & No & $0.96(0.64-1.42)$ & $0.98(0.66-1.47)$ \\
\hline & Yes & Yes & $0.70(0.56-0.88)$ & $0.71(0.57-0.90)$ \\
\hline \multirow[t]{4}{*}{ Infant length of stay $<72 \mathrm{~h}$} & Yes & Yes & 1.00 & 1.00 \\
\hline & Yes & No & $1.87(1.34-2.59)$ & $2.12(1.48-3.03)$ \\
\hline & No & Yes & $1.39(1.05-1.84)$ & $1.49(1.10-2.00)$ \\
\hline & No & No & $1.95(1.39-2.70)$ & $2.30(1.58-3.35)$ \\
\hline \multirow[t]{3}{*}{ Birth year } & - & 2012-2013 & 1.00 & 1.00 \\
\hline & - & 2007-2009 & $0.33(0.25-0.44)$ & $0.55(0.42-0.73)$ \\
\hline & - & 2010-2011 & $0.42(0.33-0.54)$ & $0.69(0.54-0.87)$ \\
\hline \multirow[t]{4}{*}{ Cesarean delivery } & No & No & 1.00 & 1.00 \\
\hline & No & Yes & $1.43(0.92-2.20)$ & $1.49(0.87-2.55)$ \\
\hline & Yes & No & $1.81(1.07-3.03)$ & $1.02(0.64-1.63)$ \\
\hline & Yes & Yes & $0.96(0.78-1.32)$ & $0.67(0.49-0.91)$ \\
\hline
\end{tabular}

change in recent years in Nova Scotia hospitals surrounding breastfeeding may have played a role. Women who delivered in nontertiary health care centres in their second pregnancy had lower odds of breastfeeding, and this may be due to fewer supports available in these communities surrounding the "Baby Friendly Initiative," which encourages practices such as less pacifier use and early breast contact. Although the breast feeding policy in Nova Scotia was enacted in $2005,{ }^{24}$ efforts toward achieving the "Baby Friendly Initiative" designation have been proceeding slowly. To date, no hospital in the province has been awarded the Baby Friendly Initiative designation, but many hospitals in the province have been awarded the Baby Friendly Initiative "certificate of participation." In the more recent years of the study period, hospitals have committed resources toward staff education, emphasis on skin-toskin contact, and other practices to improve breastfeeding.

\section{Strengths and limitations}

The strengths of this study included the large, populationbased cohort, the ability to look at breastfeeding initiation changes between a first and second birth and the separation of factors to show the direction of change over time. The NSAPD has been validated, and most pregnancy and newborn conditions were found to be accurately coded. ${ }^{20}$ Although breastfeeding was not a variable that was evaluated in the formal validation study, routine chart audits are conducted, and the breastfeeding variable was not identified as a problematic code. The results of our study are likely generalizable to other Canadian provinces and to other countries with similar universal health care coverage and similar hospital discharge practices. In addition, similarities of our results with results from other jurisdictions lend support to the generalizability of the findings. . $^{8,16,18}$

Limitations of the study include the lack of information on individual sociodemographic variables, such as education level, and on breastfeeding experience beyond discharge from hospital following the first birth. Social factors such as spousal support and opinions on the quality of education and care around breastfeeding provided by health care workers were not available in the NSAPD and could be relevant to breastfeeding initiation in a subsequent birth. With the large sample size and a large number of analyses conducted, it is possible that some of the findings were statistically, but not clinically, significant, or were statistically significant by chance (e.g., type 1 error). We required that the explanatory variables not be missing for both births, resulting in substantially reduced sample size, particularly for the model that showed changes in women who changed from initiation in the first birth to noninitiation in the second birth. In examining potential bias created by excluding missing values, we compared the proportion of women who breastfed in the second birth among those with missing covariate information and among those with nonmissing covariate information. The rates of not initiating breastfeeding in the second birth (among the subset of women who breastfed in the first birth) were $10.4 \%$ and $10.2 \%$ among women who did not have missing data and among women with missing data, respectively. The rates of initiating breastfeeding in the second birth (among the subset of women who did not breastfeed in the first birth) were similar between those without missing data and those women who were excluded because of missing data $(26.7 \%$ and $23.7 \%$, respectively). Therefore, we feel that the reduced sample due to 
missing data did not contribute to bias with respect to the breastfeeding status in the second birth.

\section{Conclusion}

Most women continue with the same feeding practices between their first 2 births. Our study identified factors associated with changes in feeding practices between the first 2 births. Although it appears that maternal lifestyle and sociodemographic factors play an important role in changing from breastfeeding in the first birth to nonbreastfeeding in the second birth, future research should consider whether breastfeeding experiences from the first birth may differentially affect women with these characteristics. The finding that cesarean delivery in both pregnancies was a significant factor in both subgroups of women suggests that future research should focus on interventions for improved breastfeeding initiation among women who have a repeat cesarean.

\section{References}

1. Caring for Kids: Breastfeeding. Ottawa: Canadian Paediatric Society; 2014. Available: www.caringforkids.cps.ca/handouts/breastfeeding (accessed 2016 Aug. 10).

2. Fifty-Fourth World Health Assembly. Global strategy for infant and young child feeding. The optimal duration of exclusive breastfeeding. Geneva: World Health Organization; 2001. Available: http://apps.who.int/gb/archive/pdf files/WHA54/ea54id4.pdf (accessed 2017 Jan. 5)

3. Horta BL, Victora CG. Short-term effects of breastfeeding: a systematic review on the benefits of breastfeeding on diarrhoea and pneumonia mortality. Geneva: World Health Organization; 2013. Available: http://apps.who.int/ iris/bitstream/10665/95585/1/9789241506120_eng.pdf?ua=1 (accessed 2017 Jan. 5).

4. Ball TM, Bennett D. The economic impact of breastfeeding. Pediatr Clin North Am 2001;48:253-62.

5. Breastfeeding initiation in Canada: key statistics and graphics (2009-2010). Ottawa: Health Canada; [modified 2012]. Available: www.hc-sc.gc.ca/fn-an/ surveill/nutrition/commun/prenatal/initiation-eng.php (accessed 2017 Jan. 5).

6. Brown CR, Dodds L, Attenborough R, et al. Rates and determinants of exclusive breastfeeding in first 6 months among women in Nova Scotia: a population-based cohort study. CMA7 Open 2013;1:E9-17.

7. Lutsiv O, Pullenaygum E, Foster G, et al. Women's intentions to breastfeed: a population-based cohort study. B7OG 2013;120:1490-8.

8. Bentley JP, Bond D, de Vroome M, et al. Factors associated with recurrent infant feeding practices in subsequent births: a population-based longitudinal study. 7 Hum Lact 2016;32:721-9.

9. Odom EC, Li R, Scanlon K, et al. Reasons for earlier than desired cessation of breastfeeding. Pediatrics 2013;131:e726-32.

10. Stuebe AM. Enabling women to achieve their breastfeeding goals. Obstet Gynecol 2014;123:643-52.

11. Hauff LE, Leonara SA, Rasmussen KM. Associations of maternal obesity and psychosocial factors with breastfeeding intention, initiation and duration. $\mathrm{Am}$ 7 Clin Nutr 2014;99:524-34.
12. Sipsma HL, Magriples U, Divney AA, et al. Breastfeeding behavior among adolescents: initiation, duration and exclusivity. 7 Adolesc Health 2013;53: 394-400.

13. Brown CR, Dodds L, Legge A, et al. Factors influencing the reasons why mothers stop breastfeeding. Can 7 Public Health 2014;105:e179-85.

14. Nickel NC, Martens P, Chateau D, et al. Have we left some behind? Trends in socio-economic inequalities in breastfeeding initiation: a population-based epidemiological surveillance study. Can 7 Public Health 2014;105:e362-8.

15. Biro MA, Yelland J, Brown S. Why are young women less likely to breastfeed? Evidence from an Australian population-based survey. Birth 2014; 41:245-53.

16. Sutherland T, Pierce C, Blomquist J, et al. Breastfeeding practices among first-time mothers across multiple pregnancies. Matern Child Health 72012 16:1665-71.

17. Phillips G, Brett K, Mendola P. Previous breastfeeding practices and duration of exclusive breastfeeding in the United States. Matern Child Health 72011 ; 15:1210-6.

18. Kruse L, Denk C, Feldman-Winter L, et al. Longitudinal patterns of breastfeeding initiation. Matern Child Health 7 2006;10:13-8.

19. Nova Scotia Atlee Perinatal Database Report of Indicators, 2005-2014. Halifax: Dalhousie University; 2015. Available: http://rcp.nshealth.ca/sites/default/files/ publications/nsapd_indicator_report_2005_2014.pdf (accessed 2017. Jan. 5).

20. Joseph KS, Fahey J. Validation of perinatal data in the Discharge Abstract Database of the Canadian Institute for Health Information. Chronic Dis Can 2009;29:96-100.

21. Labbok M, Krasovec K. Toward consistency in breastfeeding definitions. Stud Fam Plann 1990;21:226-30.

22. Tsai LC, Doan T. Breastfeeding among mothers on opioid maintenance treatment: a literature review. 7 Hum Lact 2016;32:521-9.

23. Wilson RD, Audibert F, Brock JA, et al. Pre-conception folic acid and multivitamin supplementation for the primary and secondary prevention of neural tube defects and other folic acid sensitive congenital anomalies. 7 Obstet Gynaecol Can 2015;37:534-52.

24. Policy statement: breastfeeding in Nova Scotia: responsibilities of the Nova Scotia department of health and the Nova Scotia department of health promotion and protection. Halifax: Nova Scotia Health Promotion and Protection; 2005. Available: http://novascotia.ca/dhw/healthy-development/documents/Provincial-Breast feeding-Policy.pdf (accessed 2016 Aug. 10)

Affiliations: Faculty of Medicine (Nix); Departments of Obstetrics \& Gynecology and Pediatrics (Dodds), Dalhousie University, Halifax, NS

Contributors: Kimberly Nix helped with the design of the study, conducted the analyses, contributed to the interpretation of the results and wrote the first draft of the manuscript. Linda Dodds designed the study, helped with the interpretation of results and critically revised the manuscript. Both authors have seen and approved the final version of the manuscript and agreed to act as guarantors of the results.

Acknowledgements: The authors thank the Reproductive Care Program of Nova Scotia for access to the data. This research study was undertaken as part of the Research in Medicine program, Dalhousie University for Kimberly Nix. She received a summer research stipend from the Faculty of Medicine at Dalhousie University.

Supplemental information: For reviewer comments and the original submission of this manuscript, please see www.cmajopen.ca/content/5/1/ E213/suppl/DC1 